\title{
An Examination of the Association Between Psychopathy and Dissimulation Using the MMPI-2-RF Validity Scales
}

\author{
Brandee E. Marion, Martin Sellbom, and \\ Randall T. Salekin \\ University of Alabama
}

Joseph A. Toomey and L. Thomas Kucharski John Jay College of Criminal Justice

\author{
Scott Duncan \\ United States Penitentiary, Atlanta, Georgia
}

\begin{abstract}
This investigation sought to determine whether individuals high on psychopathic traits are better able than those low on such traits to avoid detection when feigning psychopathology in the context of a forensic psychological evaluation. Study 1 tested whether individuals high on psychopathy were better able than those low on psychopathy to avoid detection by the Minnesota Multiphasic Personality Inventory 2-Restructured Form's (MMPI-2-RF; Ben-Porath, Y. S., \& Tellegen, A., 2008, Minnesota Multiphasic Personality Inventory-2 Restructured Form: Manual for administration, scoring and interpretation, Minneapolis, MN: University of Minnesota Press.) overreporting (F-r, $\mathrm{F}_{\mathrm{p}}-\mathrm{r}$ ) and underreporting (L-r and K-r) validity scales, when undergraduate students were asked to feign good, feign bad, or respond honestly. Study 2 aimed to replicate and extend the overreporting (F-r and $F_{p}-r$ ) analyses in a forensic pretrial sample, in which individuals were classified as malingering or not malingering using the Structured Interview of Reported Symptoms (SIRS; Rogers, R., Bagby, R. M., \& Dickens, S. E., 1992, Structured Interview of Reported Symptoms. Tampa, FL, Psychological Assessment Resources.). Combined results indicated that psychopathy did not affect the utility of the MMPI-2-RF validity scales in detecting overreporting. The underreporting analyses indicated that psychopathy did not affect the utility of L-r; however, callous-aggressive (or "meanness") psychopathy traits moderated the utility of K-r in detecting those feigning psychological adjustment, such that K-r was better able to detect individuals high on, rather than low on, psychopathy when underreporting. These results are promising in terms of evidence that individuals high on psychopathic traits are not any better than individuals low on these traits in feigning during psychological evaluations.
\end{abstract}

Keywords: psychopathy, overreporting, underreporting, response bias, MMPI-2-RF

The psychopathic personality is characterized by an array of maladaptive attributes and behaviors (Hare, 1996). These include affective-interpersonal features (i.e., callousness, superficiality, and lack of remorse or empathy) and antisocial behavior styles (i.e., sensation seeking, impulsivity, and lack of responsibility; Hare, 1996). On the surface, psychopathic individuals often appear normal or even charming, whereas, in reality, they tend to be guiltless, with no regard for the feelings or welfare of other people (Hare, 1996). Psychopathic individuals are more likely to engage in criminal behavior at a young age, and are responsible for a large proportion of violent crime and violent recidivism (Leistico, Salekin, DeCoster, \& Rogers, 2008; Walters, 2003).

Because psychopathic individuals often have police contact or are involved in the criminal justice system in some way, they

This article was published Online First July 16, 2012.

Brandee E. Marion, Martin Sellbom, and Randall T. Salekin, Department of Psychology, University of Alabama; Joseph A. Toomey and L. Thomas Kucharski, Department of Psychology, John Jay College of Criminal Justice; Scott Duncan, United States Penitentiary, Atlanta, Georgia.

Correspondence concerning this article should be addressed to Brandee E. Marion, University of Alabama, Department of Psychology, Box 870348, Tuscaloosa, AL 35487. E-mail: bemarion@crimson.ua.edu occasionally undergo forensic psychological evaluations (Hare, 2003). One of the concerns regarding psychopathic individuals is that they may distort information obtained in either interviews or self-report measures because of their manipulative and deceptive interpersonal style. In addition, because they are thought to be parasitic in nature, they may attempt to obtain unwarranted resources (medication). Because of these concerns regarding veracity, as well as the need to obtain accurate psychological information on these individuals because of the potential risk they may pose to society, it is vital that psychologists are able to accurately evaluate these individuals (Edens, 2006). By examining how individuals high on psychopathic personality traits respond during psychological evaluations, researchers can improve methods for accurately assessing these individuals for things relevant in a forensic evaluation, such as psychopathology and personality traits. In this article, we provide further information on the relation between psychopathy and deception.

\section{Psychopathy and Deceitfulness}

Deceitfulness is a key behavioral component of psychopathy. Psychopaths frequently use deception as a means to manipulate others for their own personal gain (Hare, 1993). Some psychopaths 
even lie for the thrill of it (Hare, 1993) or for what Ekman (1985) refers to as "duping delight." They often show no shame when caught in a lie, but instead are proud of their ability to deceive others without being discovered (Hare, 1993, 2003).

Psychopathic individuals may also be motivated to use deception in a variety of situations where they must undergo some form of a forensic psychological evaluation (Rogers \& Cruise, 2000). For instance, in both forensic and clinical contexts, individuals may attempt to affect the outcome of assessments by presenting themselves in an overly negative or positive light. Individuals may accomplish this by engaging in various forms of response distortion (i.e., malingering or defensiveness) on psychological assessments (Bagby, Marshall, Bury, Bacchiochi, \& Miller, 2006).

Overreporting, often referred to as malingering in light of an external incentive, involves the embellishment of psychological problems in order to appear mentally ill (Rogers, 2008). For instance, defendants on trial for criminal charges could attempt to present themselves in an overly negative light to gain the sympathy of a jury or to be declared not guilty by reason of insanity (Iverson, Franzen, \& Hammond, 1995). Personal injury litigants, employees claiming workers' compensation benefits, and/or social security disability applicants may overreport or exaggerate symptoms of mental illness in order to gain compensation (Bagby et al., 2006; Iverson et al., 1995; Wygant et al., 2009). Prisoners may overreport psychological problems in order to affect the duration of their sentence, placement (i.e., lower security level or a mental health facility), and responsibilities in prison (i.e., work detail; Iverson et al., 1995).

On the other hand, underreporting, commonly referred to as defensiveness when intentional, can involve minimizing or denying psychopathology as well as claiming unlikely virtues (Bagby et al., 2006; Rogers, 2008). Incarcerated individuals might minimize psychological problems or aggressive proclivities in order to be granted parole. Parents may deny psychological problems and endorse unlikely virtues (e.g., minor personal faults and shortcomings to which most people will admit) in order to sway the decision of a judge during child custody litigation. Job applicants may underreport problems or highlight their strengths in order to increase the probability of being hired (Sellbom \& Bagby, 2008b).

\section{Detection of Response Bias via Self-Report Inventories}

Some psychological test instruments have been developed specifically to assess different response styles, such as the Structured Interview of Reported Symptoms (SIRS; Rogers et al., 1992). In addition, a number of widely used omnibus personality inventories employ validity scales to detect various forms of response bias (see Sellbom \& Bagby, 2008a, for a review). Of these, the Minnesota Multiphasic Personality Inventory (MMPI; Hathaway \& McKinley, 1940) was one of the first self-report measures to include validity scales (Baer \& Miller, 2002). Its successors, the MMPI-2 (Butcher et al., 2001) and MMPI-2 Restructured Form (MMPI-2RF; Ben-Porath \& Tellegen, 2008) also include validity scales.

The validity scales on the MMPI-2-RF include revised versions of MMPI-2 scales (along with one new scale), which are specifically designed to detect over- and underreporting of psychological problems (Gervais, Ben-Porath, Wygant, \& Sellbom, 2010; Sellbom \& Bagby, 2008b, 2010; Sellbom, Toomey, Wygant, Kucharski, \& Duncan, 2010; Wygant et al., 2009, 2010). Two MMPI2-RF scales designed to detect overreporting of psychopathology were used in the current investigation. The Infrequent Responses (F-r) scale is used as a general indicator of overreporting of psychological problems (Wygant et al., 2009). The Infrequent Psychopathology Responses $\left(\mathrm{F}_{\mathrm{P}}-\mathrm{r}\right)$ scale identifies overreporting of severe psychopathology (Sellbom et al., 2010). Two MMPI2-RF scales designed to detect underreporting were also used in the current study. The Uncommon Virtues (L-r) scale detects denial of minor personal faults and shortcomings to which most people will admit. Elevated scores on K-r indicate that the individual presented him- or herself as well adjusted. The current study was specifically focused on determining whether individuals high on psychopathy were better able to avoid detection of these scales relative to those low on psychopathy.

\section{Psychopathy and the Ability to Feign}

In regard to overreporting, some research (e.g., Kucharski, Duncan, Egan, \& Falkenbach, 2006; Poythress, Edens, \& Watkins, 2001) has indicated that those high on psychopathic traits scored higher than those low on such traits on some measures of malingering, such as the MMPI-2's Infrequency (F) and F-K Index, the SIRS, and the Negative Impression Management (NIM) scale of the Personality Assessment Inventory (PAI; Morey, 1991, 2007). However, those high on psychopathic traits did not score significantly higher than those low on psychopathy on other overreporting indices (Kucharski et al., 2006), such as the MMPI-2's BackInfrequency $\left(\mathrm{F}_{\mathrm{B}}\right)$ and Infrequency Psychopathology $\left(\mathrm{F}_{\mathrm{p}}\right)$ and the PAI's Malingering Index (MAL; Morey, 1996). Other studies (e.g., Book, Holden, Starzyk, Wasylkiw, \& Edwards, 2006, and MacNeil \& Holden, 2006) indicate that psychopathy is not associated with the ability to successfully "fake bad." Book and colleagues (2006) found no difference in level of psychopathic personality traits for individuals able to successfully present themselves in a negative light when asked to "fake bad" on the Holden Psychological Screening Inventory (HPSI; Holden, 1996). MacNeil and Holden (2006) found no significant differences in level of psychopathy between individuals who successfully and unsuccessfully faked good or bad on the HPSI (as classified using cutoff scores on the HPSI's validity index as well as the Impression Management [IM] scale of the Balanced Inventory of Desirable Responding [BIDR; Paulhus, 1998]). Thus, research regarding the association between psychopathic traits and overreporting has resulted in contradictory evidence.

With regard to underreporting, some studies have shown that psychopathy may be linked to increased ability to successfully present themselves in a positive light, while others have found no such association. Those high on psychopathic traits have been shown to significantly lower their psychopathy scores when asked to present in a positive light, while those low on psychopathic traits were not able to do so (Edens, Buffington, Tomicic, \& Riley, 2001). Book and colleagues (2006) instructed individuals to "fake good" on the HPSI. Individuals in the "fake good" group who successfully faked good (i.e., scored below cutoff on the HPSI's validity index) scored significantly higher on psychopathy than those who were identified as faking good (i.e., scored above cutoff on the HPSI's validity index). MacNeil and Holden (2006) found no difference in general psychopathy (as measured by Psychopathic Personality Inventory [PPI; Lilienfeld \& Andrews, 1996] total score) between individuals who successfully or unsuccessfully faked good on the HPSI. However, those who avoided 
detection while faking good scored higher on the Machiavellian Egocentricity and Blame Externalization, and lower on Stress Immunity subscales of the PPI. Thus, psychopathy (particularly various traits or aspects of the psychopathy construct) may have differential influence on an individual's ability to avoid detection when underreporting psychopathology.

It should be noted that these studies have significant methodological limitations. Some of the previously cited studies (e.g., Poythress et al., 2001) had small sample sizes, which could have resulted in Type II errors. Other studies (e.g., Book et al., 2006; MacNeil \& Holden, 2006) used measures without well-established utility in detecting response styles (e.g., the Holden Psychological Screening Inventory's [Holden, 1996] Validity Index), which could have resulted in substantial misclassification of participants. Poythress and colleagues (2001) relied on previously established clinician classifications of malingering of unknown reliability, instead of using a standardized methodology, which also could have resulted in misclassification. Furthermore, all previous studies have used only one measure to index psychopathy, which does not account for the variety in conceptualization of this construct. Some of these studies used a within-subjects design (e.g., Edens et al., 2001; MacNeil \& Holden, 2006), which provides the potential for practice effects. Most of these studies (except Poythress et al., 2001) relied on an analogue simulation design, which Rogers (2008) indicates may decrease generalizability, because the individuals may not have sufficient motivation to over- or underreport.

\section{The Current Investigation}

The goal of this investigation was to examine the association between psychopathy and response bias within the context of a forensic psychological evaluation. To date, no study has investigated whether psychopathy moderates the utility of validity scales (i.e., MMPI-2-RF F-r, $\mathrm{F}_{\mathrm{P}}$-r, L-r, and K-r scales) in differentiating between individuals who over- or underreport and honest respondents, such that individuals higher on psychopathic personality traits would be better at avoiding detection than individuals low on such traits. Such moderation would be indicative of enhanced ability of those high on psychopathy in being more adept at deception.

We also sought to address the methodological issues present in the previous studies. The current investigation included two samples sufficiently large enough for the planned statistical analyses. Overreporting (in both studies) and underreporting (Study 1 only) of psychopathology were assessed using the MMPI-2-RF Validity scales, which have proven utility in detecting such response styles (e.g., Gervais et al., 2010; Marion, Sellbom, \& Bagby, 2011; Sellbom \& Bagby, 2008b, 2010; Sellbom et al., 2010; Wygant et al., 2009, 2010). Study 1 used an analogue simulation design, which included a control group of individuals who completed the MMPI-2-RF under standard instructions. We also replicated the overreporting analyses in a known-groups design (criminal defendants classified as malingering vs. not malingering using the SIRS) to make these results more generalizable to clinical populations. Both studies utilized a cross-sectional between-subjects approach in order reduce practice effects that might have been encountered in previous studies where participants completed the same inventory under different sets of instructions (e.g., Edens et al., 2001; MacNeil \& Holden, 2006).
The first study included multiple means of assessing psychopathy, in order to obtain an accurate reflection of psychopathic personality traits for each participant. Due to the lack of a "gold standard" self-report psychopathy measure for use in nonincarcerated populations, Study 1 utilized a combined score from several psychopathy measures from different conceptual perspectives. In contrast, the second study used the well-established Psychopathy Checklist-Revised (PCL-R; Hare, 1991, 2003). The PCL-R is the most extensively validated measure in forensic samples and was therefore most appropriate for use in Study 2.

Only one study to date (MacNeil \& Holden, 2006) has specifically examined different facets of psychopathy (as measured by the eight subscales of the PPI) and their relationship to detection avoidance. The current investigation assessed psychopathy using multiple measures, and examined the three major domains (affective, interpersonal, and behavioral) of psychopathy to determine if any increased detection avoidance could be attributable to one particular facet.

In terms of overreporting, we expected that psychopathy would not moderate the validity scale (F-r and $\mathrm{F}_{\mathrm{p}}-\mathrm{r}$ ) scores' utility in differentiating overreporters from honest responders. However, in regard to underreporting, we expected that psychopathy would have a moderating effect for the utility of the validity scales (L-r and K-r) in differentiating underreporters from honest responders, such that individuals high on psychopathy would be better able than those low on psychopathy to avoid detection on the validity scales (e.g., Book et al., 2006; Edens et al., 2001). Thus, we expected that individuals high on psychopathic personality traits would be better able to underreport symptoms of psychopathology without being detected than they would be able to overreport psychopathology.

\section{Study 1}

\section{Method}

Participants and procedure. This study implemented an analog simulation design to determine if psychopathy moderates the utility of the MMPI-2-RF's F-r, $F_{\mathrm{P}}-\mathrm{r}$, L-r, and K-r validity scales to differentiate between individuals asked to either over- or underreport from those who took the test honestly. Although it is imperative to include a psychiatric patient control group (for overreporting analyses) when evaluating the ultimate utility of validity scales, it was deemed less necessary in this investigation because the focus was on a moderation effect rather than specifically evaluating the validity of individual RF validity scales in truly differentiating between feigners and patients. In fact, a control group with different levels of psychopathy than this general sample might actually introduce a confounding variable. According to recommendations from Ben-Porath and Tellegen (2008), we excluded invalid MMPI-2-RF protocols based on elevated Cannot Say $($ CNS-r) $>17$, Variable Response Inconsistency (VRIN-r) $>$ 79T, or True Response Inconsistency (TRIN-r) $>$ 79T scores. Profiles were also excluded if individuals reported inadequate understanding of the study or poor compliance with instructions, as determined by responses on the posttest questionnaire.

The final sample consisted of male $(n=154)$ and female $(n=$ 311 ) undergraduate students with ages ranging from 18 to 40 years $(M=19.08, S D=1.84)$. Participants were primarily Caucasian (84.3\%) or African American (11.0\%), with the remaining $4.7 \%$ of other or mixed ethnicities. The majority of this sample $(98.3 \%)$ 
reported being single and never married. Subjects were randomly assigned to the "underreporting" $(n=100)$, "overreporting" $(n=$ $119)$, and "honest" $(n=246)$ conditions. There were no statistically significant group or gender differences in the demographic variables.

After providing informed consent, participants were administered a series of self-report questionnaires. All psychopathy measures were completed under standard instructions. Participants were then presented with instructions for the MMPI-2-RF. The "honest" condition was presented with standard instructions; the "underreporting" condition was presented with instructions to present themselves in a positive light; and the "overreporting" condition was presented with instructions to present themselves in a negative light.

\section{Measures}

Psychopathic Personality Inventory-Revised (PPI-R; Lilienfeld \& Widows, 2005). The original PPI (Lilienfeld \& Andrews, 1996) is a 187-item self-report questionnaire designed to measure psychopathic personality traits in nonincarcerated samples using eight subscales. These subscales load primarily onto two factors, with the exception of the Coldheartedness subscale (Benning, Patrick, Hicks, Blonigen, \& Krueger, 2003). The Fearless Dominance factor includes subscales measuring Social Potency, Fearlessness, and Stress Immunity, while the Impulsive Antisociality factor includes subscales measuring Carefree Nonplanfulness, Impulsive Nonconformity, Machiavellian Egocentricity, and Blame Externalization. Participants indicate the degree to which they agree with statements on the following scale: 1 (false), 2 (mostly false), 3 (mostly true), or 4 (true). The PPI has wellestablished reliability and validity (e.g., Lilienfeld \& Hess, 2001; Mullins-Nelson, Salekin, \& Leistico, 2006; Vaughn, Newhill, DeLisi, Beaver, \& Howard, 2008). The PPI-R was designed to capture the same information (including all eight subscales) as the PPI, but in a shorter, 154-item version.

Triarchic Psychopathy Measure (TriPM). Patrick's (2010) TriPM is a 58 -item measure designed to measure psychopathy according to a triarchic conceptualization of psychopathy (Patrick, Fowles, \& Krueger, 2009). This conceptualization seeks to integrate differing historical perspectives of psychopathy by focusing on recurring themes. The scale emphasizes three separate facets of psychopathy: boldness, meanness, and disinhibition. The scale is currently in its infancy, but initial research has shown promising reliability and validity for this measure (e.g., Drislane, 2011; Sellbom \& Phillips, in press).

Levenson's Self-Report Psychopathy Scale (LSRP). The LSRP (Levenson, Kiehl, \& Fitzpatrick, 1995) is a 26-item selfreport inventory of psychopathic personality traits designed for use in noninstitutionalized populations. In addition to a Total Score, recent research (e.g., Brinkley, Diamond, Magaletta, \& Heigel, 2008; Sellbom, 2011) has indicated that a three-factor solution is most appropriate across both college and correctional samples (Egocentricity, Callous, and Antisocial), so these factor scores were used in the current study. Brinkley, Schmitt, Smith, and Newman (2001) showed that the LSRP correlates moderately with the PCL-R, and other studies have shown more general support for its construct validity (Levenson et al., 1995; Lynam, Whiteside, \& Jones, 1999; Sellbom, 2011).
MMPI-2-RF. The MMPI-2-RF (Ben-Porath \& Tellegen, 2008) consists of 338 true/false items that can be derived from the 567-item MMPI-2 (Butcher et al., 2001). Ben-Porath and Tellegen (2008) provide extensive reliability and validity information for the MMPI-2-RF in the technical manual. For this study, the F-r, $\mathrm{F}_{\mathrm{p}}-\mathrm{r}$, L-r, and K-r scales were employed. All scales have shown significant correlation with their MMPI-2 counterparts in a variety of samples, with correlation coefficients above .90 for F-r, $\mathrm{F}_{\mathrm{p}}-\mathrm{r}$, and L-r, and ranging from .84 to .88 for K-r (Sellbom \& Bagby, 2008b; Sellbom et al., 2010). F-r and $F_{\mathrm{P}}-\mathrm{r}$ have significantly differentiated between malingerers and nonmalingerers in multiple samples, with large effect sizes (Cohen's $d$ ) ranging from 2.11 to 2.37 for F-r, and from 2.07 to 2.34 for $\mathrm{F}_{\mathrm{P}}-\mathrm{r}$ (Sellbom et al., 2010). L-r and K-r have significantly differentiated underreporters from honest responders across multiple samples, with large effect sizes (Cohen's $d$ ) ranging from .65 to 1.13 , and from .76 to 1.44 , respectively (Sellbom \& Bagby, 2008b).

MMPI-2-RF posttest questionnaire. This 10-item questionnaire was designed for this study in order to assess participants' understanding of the study and their level of compliance with instructions.

\section{Results}

Calculation of psychopathy scores. We first sought to obtain psychopathy scores that captured a broad range of psychopathic traits from multiple measurement perspectives. Due to the fact that no "gold standard" exists for assessing psychopathic traits using a self-report format in nonincarcerated samples, we analyzed the scores from three self-report measures to determine what psychopathic traits could be captured by using a combined score from all three measures. To obtain psychopathy factor scores for each participant, we first subjected all subscales (the eight subscales of the PPI, the three factor scales of the TriPM, and the three factor scales of the LSRP) from the psychopathy measures to an exploratory factor analysis (EFA) using maximum likelihood estimation with oblique (promax) rotation. To determine the appropriate number of factors to extract, in addition to the standard Kaiser (1960) criterion of an eigenvalue above 1.00 to indicate a viable factor, we applied parallel analysis (Horn, 1965) utilizing randomly generated data. The first four eigenvalues from the actual data were 5.04, $2.59,1.48$, and 0.97 ; the corresponding first four 95th percentile random data eigenvalues were $1.23,1.17,1.14$, and 1.10 , indicating the retention of three factors for rotation as the optimal solution. The three-factor model was also conceptually most defensible and was therefore chosen. Subscales loading on the three factors capture content indicative of: (a) disinhibitory and impulsive personality characteristics, (b) a mean or coldhearted interpersonal style, and (c) a bold or fearless personality. This factor structure aligns well with the triarchic model of psychopathy (Patrick, 2010; Patrick et al., 2009), which includes the three domains of Disinhibition, Meanness, and Boldness. Indeed, each of the three factors was anchored by one of the TriPM scales, and the additional subscales loading on each factor capture similar or relevant material to each of these domains. Table 1 displays the results of the EFA.

We used a cutoff of $|.30|$ to determine if a scale loaded on a factor, and subscales with dual loadings were only included in the calculation of the factor score for which they had the highest 
Table 1

Eigenvalues and Factor Loadings for Exploratory Factor Analysis of Psychopathy Scales

\begin{tabular}{lccc}
\hline & $\begin{array}{c}\text { Disinhibition } \\
(35.96 \%)\end{array}$ & $\begin{array}{c}\text { Meanness } \\
(18.49 \%)\end{array}$ & $\begin{array}{c}\text { Boldness } \\
(10.57 \%)\end{array}$ \\
\hline TriPM Disinhibition & $\mathbf{. 8 3}$ & & \\
LSRP Antisocial & .77 & & \\
PPI-R Blame Externalization & $\mathbf{. 6 1}$ & & \\
PPI-R Rebellious Nonconformity & $\mathbf{. 5 7}$ & & \\
PPI-R Carefree Nonplanfulness & $\mathbf{. 5 3}$ & & \\
PPI-R Coldheartedness & -.32 & $\mathbf{. 9 5}$ & \\
TriPM Meanness & & $\mathbf{. 7 8}$ & \\
LSRP Egocentricity & & $\mathbf{. 6 3}$ & \\
LSRP Callous & .40 & $\mathbf{. 6 1}$ & \\
PPI-R Machiavellian Egocentricity & .40 & & $\mathbf{. 9 9}$ \\
TriPM Boldness & & & $\mathbf{. 7 5}$ \\
PPI-R Social Influence & & & $\mathbf{. 6 2}$ \\
PPI-R Stress Immunity & -.30 & & $\mathbf{. 5 4}$ \\
PPI-R Fearless Dominance & &
\end{tabular}

Note. Only factor loadings equal to or greater than .30 are shown. Values in bold typeface indicate the factor for which each indicator was selected based on the highest loading.

loading. To generate overall and factor scores, we standardized and averaged the scores on each subscale for each participant.

Group differences in validity scale and psychopathy scores. We next conducted one-way Analyses of Variance (ANOVA) using three groups ("overreporting," "underreporting," and "honest") to determine if group differences were present for validity scale (F-r, F $F_{p}-r$, L-r, and K-r) and psychopathy scores (Total Score, Meanness factor, Disinhibition factor, and Boldness factor). Tukey's Honestly Significant Difference (HSD) test was used for post hoc analysis of group differences. Cohen's $d$ effect size estimates were used to characterize meaningful differences, with .20 indicating a small effect; .50, a medium effect; and .80, a large effect (Cohen, 1988). Table 2 displays these results. As expected, scores on F-r and $\mathrm{F}_{\mathrm{p}}-\mathrm{r}$ were significantly higher in the "overreporting" group relative to the other groups (all Cohen's $d \mathrm{~s}>3.04$ ), whereas scores on L-r and K-r were significantly higher in the "underreporting" group relative to the other groups (all Cohen's $d \mathrm{~s}>.59$ ). The overreporting scales (F-r and $\mathrm{F}_{\mathrm{p}}-\mathrm{r}$ ) differentiated overreporters from honest responders very well (Cohen's $d=-3.70$ and -3.46 , respectively). The underreport- ing scales (L-r and K-r) also differentiated underreporters from honest responders well (Cohen's $d=-.67$ and -.71 , respectively), though the effect size estimates were not nearly as high as those for the overreporting scales. Also as expected, the "overreporting," "underreporting," and "honest" groups were not significantly different on any of the psychopathy scores, due to random assignment of participants to groups.

Psychopathy as a moderator. We next conducted a series of hierarchical binomial logistic regression analyses to determine if psychopathy acted as a moderator for the ability to avoid detection by the MMPI-2-RF validity scales. Separate regression analyses were conducted for the four MMPI-2-RF validity scales and the psychopathy scores (total and three factors). Table 3 displays the results of these analyses. In terms of predicting overreporting, one of the two MMPI-2-RF overreporting scales (F-r and $\mathrm{F}_{\mathrm{P}}-\mathrm{r}$ ) and the psychopathy score (total or factor score) were entered in the first step, and the meancentered interaction term (i.e., cross-product) of the psychopathy score and MMPI-2-RF scale score in the second step, as predictors for the dichotomous outcome of either "overreporting" or "not overreporting." The same procedure was used for underreporting analysis, except the MMPI-2-RF L-r and K-r scales were used. A moderation effect was deemed present by a statistically significant increase in model fit (i.e., $\chi^{2}$ change) and a Nagelkerke-estimated $\Delta R^{2} \geq .02$ (Cohen, 1988). We used the Nagelkerke-estimated $R^{2}$ rather than a nonparametric effect size to capitalize on Cohen's (1988) guidance on what constitutes meaningful incremental prediction. Furthermore, given the number of predictions in each equation, we set an a priori conservative alpha level of .01. For the overreporting analyses, the interaction terms were not associated with meaningful incremental change in predictive utility. This indicated that, as expected, psychopathy did not moderate the validity scale scores' utility in differentiating overreporting from honestresponding participants.

For the underreporting scales, no meaningful incremental change was present for L-r. Only two interaction terms, both for the K-r scale, met the criteria for a meaningful incremental change provided by the interaction term between validity scale and psychopathy score. This interaction evidenced incremental utility when the "Meanness" factor $\left(\Delta R^{2}>.02, \chi^{2}\right.$ chg significant at $p<$

Table 2

Means, Standard Deviations, F-tests, and Effect Sizes for Honest, Underreporting, and Overreporting Groups

\begin{tabular}{lccccccc}
\hline & $\begin{array}{c}\text { Honest } \\
(n=246)\end{array}$ & $\begin{array}{c}\text { Underreporting } \\
(n=100)\end{array}$ & $\begin{array}{c}\text { Overreporting } \\
(n=119)\end{array}$ & $F$ & $d_{1}[95 \% \mathrm{CI}]$ & $d_{2}[95 \% \mathrm{CI}]$ & $d_{3}[95 \% \mathrm{CI}]$ \\
\hline $\mathrm{F}-\mathrm{r}$ & $58.73_{\mathrm{a}}(14.09)$ & $49.63_{\mathrm{b}}(8.64)$ & $148.36_{\mathrm{c}}(30.00)$ & $786.71^{*}$ & $0.66[0.47,0.95]$ & $-3.70[-4.02,3.33]$ & $-3.48[-3.90,-3.06]$ \\
$\mathrm{F}_{\mathrm{P}} \mathrm{r}$ & $61.15_{\mathrm{a}}(8.18)$ & $56.88_{\mathrm{a}}(5.91)$ & $159.35_{\mathrm{b}}(23.64)$ & $669.93^{*}$ & $0.35[0.10,0.57]$ & $-3.46[-3.80,-3.13]$ & $-3.05[-3.43,-2.65]$ \\
$\mathrm{L}-\mathrm{r}$ & $52.40_{\mathrm{a}}(9.66)$ & $59.65_{\mathrm{b}}(14.01)$ & $52.40_{\mathrm{a}}(11.11)$ & $17.48^{*}$ & $-0.67[0.43,0.90]$ & $0.02[-0.20,0.24]$ & $0.60[0.32,0.87]$ \\
K-r & $46.04_{\mathrm{a}}(8.93)$ & $52.56_{\mathrm{b}}(9.97)$ & $34.72_{\mathrm{b}}(6.53)$ & $125.90^{*}$ & $-0.71[-0.95,-0.47]$ & $1.39[1.15,1.63]$ & $2.18[1.83,2.50]$ \\
Disinhibition & $0.15(3.51)$ & $0.27(4.16)$ & $-0.53(3.61)$ & 1.71 & $-0.03[-0.26,0.20]$ & $0.19[-0.03,0.41]$ & $0.21[0.06,0.47]$ \\
Meanness & $0.19(3.92)$ & $-0.20(4.65)$ & $-0.23(3.88)$ & 0.58 & $0.09[-0.14,0.33]$ & $0.11[-0.11,0.33]$ & $0.01[-0.27,0.26]$ \\
Boldness & $0.18(3.09)$ & $-0.30(3.67)$ & $-0.13(3.11)$ & 0.97 & $0.15[-0.09,0.38]$ & $0.10[-0.12,0.32]$ & $-0.05[-0.32,0.22]$ \\
Psychopathy total & $0.21(3.38)$ & $-0.13(4.23)$ & $-0.33(3.51)$ & 1.00 & $0.09[-0.14,0.33]$ & $0.16[-0.06,0.38]$ & $0.05[-0.21,0.32]$ \\
\hline
\end{tabular}

Note. Means with different subscripts are significantly different at $p<.05$. CI $=$ confidence interval for Cohen's $d$; $d_{1}=$ effect size for honest versus underreporting groups; $d_{2}=$ Effect size for honest versus overreporting groups; $d_{3}=$ effect size for overreporting versus underreporting groups. $* p<.001$. 
Table 3

Hierarchical Logistic Regression Analyses Predicting Overreporting Versus Not Overreporting, or Underreporting Versus Not Underreporting, Using Validity Scale, Psychopathy, and Psychopathy $\times$ Validity Scale

\begin{tabular}{|c|c|c|c|c|c|c|c|c|c|c|}
\hline \multicolumn{11}{|c|}{ Full model (Final logit weights) } \\
\hline \multirow{2}{*}{$\begin{array}{l}\text { Psychopathy } \\
\text { score }\end{array}$} & \multicolumn{2}{|r|}{ F-r } & \multicolumn{2}{|c|}{ Psychopathy } & \multicolumn{2}{|c|}{ F-r $\times$ Psychopathy } & \multirow[b]{2}{*}{$R^{2}$} & \multirow[b]{2}{*}{$x^{2}$} & \multirow[b]{2}{*}{$\Delta R^{2}$} & \multirow[b]{2}{*}{$\chi^{2}$ chg } \\
\hline & $\mathrm{b}$ & $\mathrm{OR}[\mathrm{CI}]$ & $\mathrm{b}$ & $\mathrm{OR}[\mathrm{CI}]$ & $\mathrm{b}$ & $\mathrm{OR}[\mathrm{CI}]$ & & & & \\
\hline Disinhibition & $.42^{* *}$ & $1.52[1.35,1.71]$ & $-.24^{*}$ & $0.78[0.66,0.93]$ & -.01 & $0.99[0.96,1.01]$ & .85 & 342.45 & .00 & 0.89 \\
\hline Meanness & $.39^{* * *}$ & $1.47[1.34,1.63]$ & -.16 & $0.86[0.75,0.98]$ & .01 & $1.01[0.98,1.03]$ & .84 & 337.30 & .00 & 0.24 \\
\hline Boldness & $.38^{* * *}$ & $1.46[1.32,1.61]$ & -.13 & $0.88[0.75,1.03]$ & .02 & $1.02[0.99,1.05]$ & .84 & 335.79 & .00 & 2.08 \\
\hline Total & $.40^{\text {*** }}$ & $1.49[1.34,1.65]$ & $-.23^{*}$ & $0.79[0.68,0.93]$ & .01 & $1.01[0.98,1.04]$ & .85 & 341.82 & .00 & 0.39 \\
\hline
\end{tabular}

Full model

\begin{tabular}{|c|c|c|c|c|c|c|c|c|c|c|}
\hline & \multicolumn{2}{|r|}{$\mathrm{F}_{\mathrm{p}}-\mathrm{r}$} & \multicolumn{2}{|c|}{ Psychopathy } & \multicolumn{2}{|c|}{$\mathrm{F}_{\mathrm{p}}-\mathrm{r} \times$ Psychopathy } & \multirow[b]{2}{*}{$R^{2}$} & \multirow[b]{2}{*}{$x^{2}$} & \multirow[b]{2}{*}{$\Delta R^{2}$} & \multirow[b]{2}{*}{$\chi^{2}$ chg } \\
\hline & $\mathrm{b}$ & $\mathrm{OR}[\mathrm{CI}]$ & $\mathrm{b}$ & $\mathrm{OR}[\mathrm{CI}]$ & $\mathrm{b}$ & $\mathrm{OR}[\mathrm{CI}]$ & & & & \\
\hline Disinhibition & $.63^{\text {** }}$ & $1.89[1.62,2.20]$ & -.12 & $0.89[0.78,1.01]$ & .02 & $1.12[0.97,1.06]$ & .83 & 327.66 & .00 & 0.62 \\
\hline Meanness & $.65^{* * *}$ & $1.92[1.63,2.27]$ & -.10 & $0.90[0.79,1.02]$ & .04 & $1.04[1.00,1.09]$ & .83 & 329.94 & .00 & 3.27 \\
\hline Boldness & $.64^{* * *}$ & $1.90[1.61,2.50]$ & -.11 & $0.90[0.77,1.05]$ & .04 & $1.04[1.00,1.09]$ & .83 & 328.76 & .01 & 2.95 \\
\hline Total & $.68^{* * *}$ & $1.97[1.65,2.34]$ & -.15 & $0.86[0.75,0.98]$ & .05 & $1.05[1.00,1.10]$ & .83 & 332.79 & .01 & 4.07 \\
\hline
\end{tabular}

Full model

\begin{tabular}{|c|c|c|c|c|c|c|c|c|c|c|}
\hline & \multicolumn{2}{|r|}{ L-r } & \multicolumn{2}{|c|}{ Psychopathy } & \multicolumn{2}{|c|}{ L-r $\times$ Psychopathy } & \multirow[b]{2}{*}{$R^{2}$} & \multirow[b]{2}{*}{$x^{2}$} & \multirow[b]{2}{*}{$\Delta R^{2}$} & \multirow[b]{2}{*}{$\chi^{2}$ chg } \\
\hline & $\mathrm{b}$ & $\mathrm{OR}[\mathrm{CI}]$ & $\mathrm{b}$ & $\mathrm{OR}[\mathrm{CI}]$ & $\mathrm{b}$ & $\mathrm{OR}[\mathrm{CI}]$ & & & & \\
\hline Disinhibition & $.29^{* * *}$ & $1.34[1.20,1.50]$ & .05 & $1.05[0.98,1.13]$ & .01 & $1.01[0.98,1.04]$ & .12 & 31.31 & .00 & 0.50 \\
\hline Meanness & $.28^{* *}$ & $1.32[1.18,1.47]$ & -.03 & $0.97[0.91,1.03]$ & .02 & $1.02[0.99,1.04]$ & .12 & 30.67 & .01 & 1.98 \\
\hline Boldness & $.26^{* * *}$ & $1.30[1.16,1.45]$ & -.03 & $0.97[0.90,1.05]$ & -.03 & $0.97[0.94,1.01]$ & .12 & 31.18 & .00 & 1.81 \\
\hline Total & $.28^{* * *}$ & $1.32[1.19,1.47]$ & -.01 & $0.99[0.92,1.06]$ & .02 & $1.02[0.99,1.05]$ & .12 & 29.53 & .01 & 1.15 \\
\hline
\end{tabular}

Full model

\begin{tabular}{|c|c|c|c|c|c|c|c|c|c|c|}
\hline & \multicolumn{2}{|r|}{ K-r } & \multicolumn{2}{|c|}{ Psychopathy } & \multicolumn{2}{|c|}{ K-r $\times$ Psychopathy } & \multirow[b]{2}{*}{$R^{2}$} & \multirow[b]{2}{*}{$x^{2}$} & \multirow[b]{2}{*}{$\Delta R^{2}$} & \multirow[b]{2}{*}{$\chi^{2}$ chg } \\
\hline & $\mathrm{b}$ & $\mathrm{OR}[\mathrm{CI}]$ & $\mathrm{b}$ & $\mathrm{OR}[\mathrm{CI}]$ & $\mathrm{b}$ & $\mathrm{OR}[\mathrm{CI}]$ & & & & \\
\hline Disinhibition & $.28^{* *}$ & $1.32[1.20,1.46]$ & .04 & $1.04[0.96,1.13]$ & .02 & $1.02[1.00,1.05]$ & .16 & 40.92 & .01 & 2.91 \\
\hline Meanness & $.26^{* * *}$ & $1.30[1.18,1.43]$ & -.10 & $0.91[0.83,0.99]$ & $.04^{*}$ & $1.04[1.01,1.06]$ & .17 & 43.22 & .04 & $9.58^{*}$ \\
\hline Boldness & $.30^{* *}$ & $1.35[1.22,1.49]$ & -.11 & $0.90[0.81,0.99]$ & -.02 & $0.98[0.95,1.01]$ & .18 & 45.26 & .01 & 1.40 \\
\hline Total & $.26^{* *}$ & $1.30[1.18,1.43]$ & -.09 & $0.92[0.84,1.00]$ & .03 & $1.03[1.00,1.06]$ & .15 & 39.31 & .02 & 5.47 \\
\hline
\end{tabular}

Note. Nagelkerke $R^{2}$ estimation was used for logistic regression. $\Delta R^{2}=$ change in $R^{2}$ between Step 1 (Validity scale and Psychopathy scale entered) and Step 2 (Validity scale $\times$ Psychopathy scale interaction entered); CI $=95 \%$ confidence interval for odds ratio; OR $=$ odds ratio for predictor; $\chi^{2}=$ overall $\chi^{2}$ for the equation; $\chi^{2}$ chg $=$ change in $\chi^{2}$ between Step 1 and Step 2.

${ }^{*} p<.01 .{ }^{* * *} p<.001$.

.01) was the predictor, indicating that psychopathy did moderate the validity scale scores' utility in differentiating underreporters from honest responders. Figure 1 displays the interaction between Meanness and K-r when predicting individuals' group membership (underreporting vs. honest). Although a moderating effect was found for this factor, it was actually in the opposite direction from what was expected. That is, callous-unemotional-aggressive traits were associated with a poorer ability to avoid detection by the K-r validity scale. This potentially counterintuitive effect will be considered in detail later.

We also conducted separate regression analyses to investigate the presence of gender differences in the results. To determine whether there was a moderating effect for gender, we entered gender, two two-way interaction terms that included gender, and a three-way interaction term for validity scale, gender, and psychopathy scores in subsequent steps of the regression analyses. Using our previously established criteria to determine moderation effects, these results indicated that there were no significant or meaningful differences in results across men and women.

\section{Study 2}

The primary goal of this study was to replicate a portion of the results from Study 1 using an alternative methodology and setting. This study implemented a known-groups design to determine if psychopathy moderates the utility of the MMPI-2-RF F-r and $\mathrm{F}_{\mathrm{P}}-\mathrm{r}$ Validity scales to differentiate between individuals who engaged in overreporting from those who approached the test honestly. 


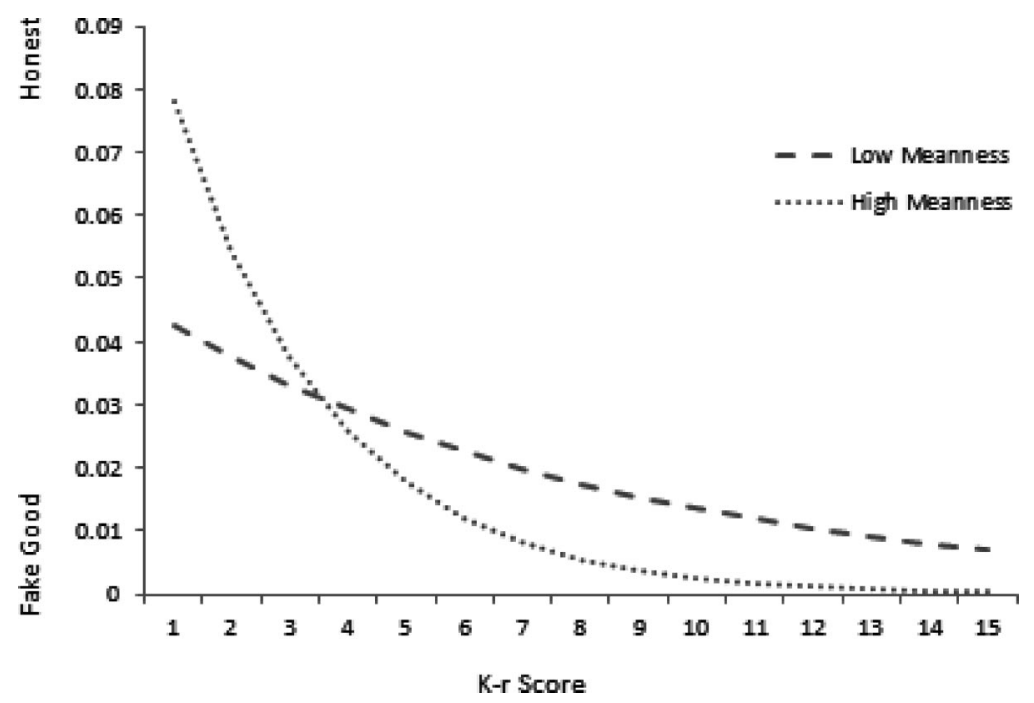

Figure 1. Interaction between meanness and K-r score in predicting honest versus feign good groups.

\section{Method}

Participants and procedure. We used an archival sample of 122 male criminal defendants who were referred by federal court between 1994 and 2004 for a forensic psychological evaluation (i.e., competency to stand trial, criminal responsibility, or aid-insentencing). This sample has been used in previous studies examining the MMPI-2 and MMPI-2-RF Validity scales (Sellbom et al., 2010; Toomey, Kucharski, \& Duncan, 2009).

Each participant completed the MMPI-2, SIRS, and PCL-R as part of their evaluation. In a similar fashion as Study 1, we excluded individuals with invalid MMPI-2-RF profiles, based on the same guidelines described for Study 1 (i.e., CNS- $r>17$, VRIN $-r>79 \mathrm{~T}$, or TRIN- $r>79 \mathrm{~T}$ indicates an invalid profile), which resulted in a final sample size of 99. Participants ranged from 20 to 64 years of age $(M=36.55, S D=10.28)$. In regard to ethnicity, participants were primarily Caucasian (58\%) or African American (39\%), with the remaining 3\% of Hispanic or other origin. Ninety-one percent had previous felony convictions. In regard to mental health treatment, $67 \%$ reported receiving previous mental health treatment, and $44 \%$ had at least one previous psychiatric hospitalization. The most common primary diagnosis was antisocial personality disorder (35\%).

Participants were classified as "overreporting" or "not overreporting" based on the SIRS manual guidelines (Rogers et al., 1992). Participants who scored in the "probable" range on three or more subscales on the SIRS, or in the "definite" range on one or more subscales, were classified as "overreporting." The remaining participants were classified as "not overreporting."

\section{Measures}

PCL-R. Hare's $(1991,2003)$ PCL-R is often considered the "gold standard" of psychopathy assessment (Lilienfeld \& Fowler, 2006). It involves a semistructured interview format, where the examiner rates the individual on 20 items indicative of psychopathic characteristics. In addition to a Total Score, the PCL-R yields two factor scores; Factor I assesses affective-interpersonal characteristics, while Factor II indexes social deviance aspects of psychopathy (e.g., impulsivity, sensation-seeking, and lack of responsibility). Hare (2003) has also described four facets underlying Factors I and II. Facets 1 and 2 separate Factor I into affective and interpersonal features, whereas Facets 3 and 4 separate Factor II into lifestyle instability and antisocial behavior features, respectively. Due to practical limitations in this setting, which included the PCL-R being administered as part of a psychological evaluation with no availability for videotaping or otherwise observing the participant, we were unable to calculate interrater reliability. However, internal consistencies (Cronbach's alpha) for the current sample were: .91 (Total), .89 (Factor I), .83 (Factor II), .74 (Interpersonal facet), .90 (Affective facet), .61 (Antisocial facet), and .79 (Lifestyle facet), indicating that some concerns regarding measurement error is mitigated.

SIRS. The SIRS (Rogers et al., 1992) is a structured interview that contains 172 items designed to index malingering and overreporting. Four classifications can be made (honest, indeterminate, probable faking, and definite faking) from each of the following eight scales: Rare Symptoms, Improbable and Absurd Symptoms, Symptom Combinations, Blatant Symptoms, Subtle Symptoms, Symptom Severity, Symptom Selectivity, and Reported versus Observed Symptoms. The SIRS has shown utility as an external criterion measure in other knowngroups studies examining overreporting (e.g., Edens, Poythress, \& Watkins-Clay, 2007; Sellbom et al., 2010). Previous studies have indicated that the SIRS is reliable, with internal consistencies ranging from .77 to .96 , and interrater reliability coefficients ranging from .97 to 1.00 (e.g., Rogers et al., 1992; Vitacco, Rogers, Gabel, \& Munizza, 2007).

MMPI-2-RF. For this sample, we scored the MMPI-2-RF validity scales using data from MMPI-2 administrations. Scores obtained from administration of the 338-item MMPI-2-RF booklet are interchangeable with MMPI-2-RF scores derived from administration of the 567-item MMPI-2 booklet (Ben-Porath \& Tellegen, 2008; Sellbom et al., 2010). 


\section{Results}

Group differences in validity scale and psychopathy scores. As with Study 1, we began with one-way ANOVAs to examine group differences in overreporting validity scale scores (F-r and $\mathrm{F}_{\mathrm{p}}-\mathrm{r}$ ) and psychopathy scores between "overreporting" and "not overreporting" groups. Table 4 displays the results of these analyses. As expected, scores on F-r and $\mathrm{F}_{\mathrm{p}}-\mathrm{r}$ were significantly higher in the "overreporting" group relative to the honest group, with large effect size estimates associated with these differences (both Cohen's $d \mathrm{~s}>2.08)$. Such differences were expected, given that Sellbom et al. (2010) used part of the current sample to examine the utility of the MMPI-2-RF validity scales in differentiating between SIRS-defined groups of overreporting and non-overreporting individuals. A few differences were present in psychopathy scores as well, such that individuals in the "overreporting" group had significantly higher PCL-R Total, Factor 1, and Affective Facet scores compared with those in the "honest" group (all $F \mathrm{~s}>4.30$, all $p \mathrm{~s}<.05$ ). Unlike in Study 1 , these individuals were not randomly assigned to groups or asked to overreport symptoms of psychopathology.

Psychopathy as a moderator. Next, we conducted a series of hierarchical binomial logistic regression analyses to determine if psychopathy acts as a moderator for the ability to avoid detection by the MMPI-2-RF validity scales. Table 5 displays the results of these regression analyses. Separate regression analyses were conducted for the two overreporting MMPI-2-RF scales (F-r and $\mathrm{F}_{\mathrm{p}}-\mathrm{r}$ ) and the PCL-R scores (total, factor, and facet scores). One of the two MMPI-2-RF overreporting validity scales (F-r and $\mathrm{F}_{\mathrm{P}}-\mathrm{r}$ ) and one of the PCL-R scores (total, factor, or facet) were entered in the first step, and a mean-centered interaction term (i.e., crossproduct) between PCL-R score and MMPI-2-RF scale in the second step, as predictors for the dichotomous outcome of either "overreporting" or "not overreporting." As with Study 1, a moderation effect was indicated by a statistically significant increase in model fit (i.e., $\chi^{2}$ change) and a Nagelkerke-estimated $\Delta R^{2}>.02$ (Cohen, 1988). As in Study 1, these results indicate that psychopathy did not moderate the validity scale scores' utility in differentiating overreporters from honest responders.

\section{General Discussion}

The goal of this investigation was to examine the relation between psychopathy and response bias. More specifically, we examined whether psychopathy acts as a moderator for the ability to avoid detection by the MMPI-2-RF validity scales when individuals over- or underreport symptoms of psychopathology, such that individuals high on psychopathic traits would be better able to avoid detection than individuals low on these traits. We found no such moderation effect for the overreporting scales or for the L-r scale. We did find that the callous-aggressive ("mean") component of psychopathy moderated the utility of the K-r scale in detecting underreporting. However, this was in the opposite direction of what we expected, such that individuals high on meanness were actually worse than those low on meanness in avoiding detection by K-r. Thus, individuals higher on psychopathic personality traits were not better able than individuals low on these traits to avoid detection on the MMPI-2-RF validity scales. In fact, those high on the callous-aggressive component of psychopathy actually performed more poorly than those low on these traits when trying to avoid detection.

Our findings regarding overreporting are consistent with those of Book et al. (2006), who found that individuals who successfully faked bad did not score significantly higher on psychopathy than those who were detected. The current findings are also consistent with those from Kucharski et al. (2006), who found that inmates high on psychopathy did not score significantly higher than those low on psychopathy on the MMPI-2's $F_{p}$ scale, but they did score higher on the MMPI-2's F scale than did those low on psychopathy. Thus, while individuals high on psychopathic traits may attempt to malinger more frequently than those low on these traits, they are not more successful at doing so.

The current overreporting findings partially contradict those from Poythress et al. (2001), who found that malingerers high on psychopathic traits were able to avoid detection on the PAI's Rogers Discriminant Function (RDF) scale but not on the NIM scale. The contradictory results between these two studies and the current investigation could be due to methodological differences, such as use of different measures. For example, the NIM scale is very similar to $F_{p}-r$ in its development (e.g., Morey, 2007), but the RDF scale is not similar to any of the MMPI-2-RF validity scales. As described earlier, F-r and $\mathrm{F}_{\mathrm{p}}-\mathrm{r}$ were constructed by examining specific items that were infrequently endorsed by normal and psychiatric populations. The RDF was developed by conducting a discriminant function analysis to look at 20 scales of the PAI and determine whether or not an individual's pattern is similar to that of a bona fide patient (Rogers, Sewell, Morey, \& Ustad, 1996). This difference in detection strategies between the MMPI-2-RF

Table 4

Means, Standard Deviations, F-tests, and Effect Sizes for Honest and Overreporting Groups

\begin{tabular}{|c|c|c|c|c|}
\hline & Honest $(n=78)$ & Overreporting $(n=21)$ & $F$ & $d[\mathrm{CI}]$ \\
\hline F-r & $8.55(6.51)$ & $21.71(5.39)$ & $72.31^{* * * *}$ & $-2.09[-2.64,-1.51]$ \\
\hline $\mathrm{F}_{\mathrm{P}}-\mathrm{r}$ & $3.14(2.73)$ & $9.76(3.85)$ & $80.93^{* * * * *}$ & $-2.21[-2.76,-1.62]$ \\
\hline PCL-R Total & $22.80(10.10)$ & $27.90(7.76)$ & $4.62^{*}$ & $-0.53[-1.01,-0.04]$ \\
\hline PCL-R Factor 1 & $8.96(5.05)$ & $11.38(3.26)$ & $4.31^{*}$ & $-0.51[-0.99,-0.02]$ \\
\hline PCL-R Factor 2 & $11.17(4.33)$ & $13.03(3.83)$ & 3.19 & $-0.44[-0.92,0.05]$ \\
\hline PCL-R Interpersonal facet & $4.04(2.83)$ & $5.05(1.66)$ & 2.44 & $-0.38[-0.87,0.10]$ \\
\hline PCL-R Affective facet & $5.05(2.71)$ & $6.38(1.94)$ & $4.44^{*}$ & $-0.52[-1.00,-0.03]$ \\
\hline PCL-R Antisocial facet & $5.29(2.54)$ & $6.43(2.75)$ & 3.23 & $-0.44[-0.92,0.05]$ \\
\hline PCL-R Lifestyle facet & $7.68(2.96)$ & $8.57(2.23)$ & 1.65 & $-0.32[-0.80,0.17]$ \\
\hline
\end{tabular}

Note. $\quad \mathrm{CI}=95 \%$ confidence interval for Cohen's $d$.

${ }^{*} p<.05 .{ }^{* * *} p<.01 .{ }^{* * *} p<.001$. 
Table 5

Hierarchical Logistic Regression Analyses Predicting Overreporting versus Not Overreporting Using Validity Scale, Psychopathy, and Psychopathy $\times$ Validity Scale

\begin{tabular}{|c|c|c|c|c|c|c|c|c|c|c|}
\hline \multicolumn{11}{|c|}{ Full model (Final logit weights) } \\
\hline \multirow[b]{2}{*}{ PCL-R score } & \multicolumn{2}{|r|}{ F-r } & \multicolumn{2}{|c|}{ Psychopathy } & \multicolumn{2}{|c|}{ F-r $\times$ Psychopathy } & \multirow[b]{2}{*}{$R^{2}$} & \multirow[b]{2}{*}{$\chi^{2}$} & \multirow[b]{2}{*}{$\Delta R^{2}$} & \multirow[b]{2}{*}{$\chi^{2}$ chg } \\
\hline & $\mathrm{b}$ & $\mathrm{OR}[\mathrm{CI}]$ & $\mathrm{b}$ & $\mathrm{OR}[\mathrm{CI}]$ & $\mathrm{b}$ & $\mathrm{OR}[\mathrm{CI}]$ & & & & \\
\hline Total & $.26^{* * *}$ & $1.29[1.16,1.45]$ & .00 & $1.00[0.91,1.11]$ & .01 & $1.01[0.99,1.02]$ & .60 & 48.07 & .01 & 0.67 \\
\hline Factor 1 & $.26^{* * *}$ & $1.30[1.16,1.45]$ & .06 & $1.06[0.85,1.33]$ & .01 & $1.01[0.99,1.04]$ & .62 & 50.44 & .01 & 0.83 \\
\hline Factor 2 & $.26^{* * *}$ & $1.30[1.16,1.45]$ & .00 & $1.00[0.79,1.26]$ & .01 & $1.01[0.98,1.03]$ & .59 & 46.83 & .01 & 0.12 \\
\hline Interpersonal facet & $.27^{* * *}$ & $1.31[1.17,1.47]$ & .12 & $1.13[0.77,1.66]$ & .02 & $1.02[0.98,1.07]$ & .62 & 50.35 & .01 & 1.06 \\
\hline Affective facet & $.26^{* *}$ & $1.29[1.16,1.45]$ & .07 & $1.08[0.72,1.60]$ & .02 & $1.02[0.98,1.06]$ & .61 & 49.78 & .00 & 0.81 \\
\hline Antisocial facet & $.26^{* * *}$ & $1.30[1.17,1.46]$ & -.03 & $0.97[0.66,1.42]$ & .02 & $1.02[0.98,1.06]$ & .59 & 47.04 & .00 & 0.52 \\
\hline Lifestyle facet & $.27^{* * *}$ & $1.32[1.17,1.48]$ & -.07 & $0.94[0.66,1.32]$ & .00 & $1.00[0.96,1.04]$ & .58 & 46.75 & .00 & 0.01 \\
\hline \multicolumn{11}{|c|}{ Full model } \\
\hline & \multicolumn{2}{|r|}{$\mathrm{F}_{\mathrm{p}}-\mathrm{r}$} & \multicolumn{2}{|c|}{ Psychopathy } & \multicolumn{2}{|c|}{$\mathrm{F}_{\mathrm{p}}-\mathrm{r} \times$ Psychopathy } & \multirow[b]{2}{*}{$R^{2}$} & \multirow[b]{2}{*}{$x^{2}$} & \multirow[b]{2}{*}{$\Delta R^{2}$} & \multirow[b]{2}{*}{$\chi^{2}$ chg } \\
\hline & $\mathrm{b}$ & $\mathrm{OR}[\mathrm{CI}]$ & $\mathrm{b}$ & $\mathrm{OR}[\mathrm{CI}]$ & $\mathrm{b}$ & $\mathrm{OR}[\mathrm{CI}]$ & & & & \\
\hline Total & $.47^{* * *}$ & $1.61[1.31,1.97]$ & .02 & $1.02[0.94,1.11]$ & .00 & $1.00[0.98,1.03]$ & .57 & 45.47 & .00 & 0.12 \\
\hline Factor 1 & $.47^{* * *}$ & $1.60[1.30,1.97]$ & .07 & $1.08[0.90,1.28]$ & .01 & $1.01[0.96,1.06]$ & .58 & 45.93 & .00 & 0.05 \\
\hline Factor 2 & $.48^{* * *}$ & $1.62[1.33,1.99]$ & .00 & $1.00[0.83,1.20]$ & .02 & $1.02[0.97,1.06]$ & .57 & 45.43 & .00 & 0.42 \\
\hline Interpersonal facet & $.48^{* * *}$ & $1.61[1.32,1.97]$ & .13 & $1.14[0.83,1.55]$ & .02 & $1.02[0.93,1.11]$ & .58 & 45.97 & .00 & 0.15 \\
\hline Affective facet & $.48^{* * *}$ & $1.61[1.31,1.98]$ & .13 & $1.13[0.81,1.58]$ & .00 & $1.00[0.92,1.10]$ & .57 & 45.69 & .00 & 0.01 \\
\hline Antisocial facet & $.49^{* * *}$ & $1.63[1.33,2.01]$ & .00 & $1.00[0.74,1.36]$ & .03 & $1.03[0.96,1.11]$ & .58 & 45.71 & .01 & 0.73 \\
\hline Lifestyle facet & $.50^{* * *}$ & $1.64[1.34,2.02]$ & -.02 & $0.98[0.74,1.30]$ & .00 & $1.00[0.92,1.08]$ & .57 & 44.94 & .00 & 0.01 \\
\hline
\end{tabular}

Note. Nagelkerke $R^{2}$ estimation was used for logistic regression. $\Delta R^{2}=$ change in $R^{2}$ between Step 1 (Validity scale and Psychopathy scale entered) and Step 2 (Validity scale $\times$ Psychopathy scale interaction entered); CI $=95 \%$ confidence interval for odds ratio; OR $=$ odds ratio for predictor; $\chi^{2}=$ overall $\chi^{2}$ for the equation; $\chi^{2}$ chg $=$ change in $\chi^{2}$ between Step 1 and Step 2.

${ }^{*} p<.01{ }^{* * *} p<.001$.

scales and the PAI's RDF could explain the inconsistent findings between Poythress et al. (2001) and the current study. It should be noted, however, that some research has indicated that the RDF is of questionable validity in forensic settings (Hawes \& Boccaccini, 2009; Sellbom \& Bagby, 2008a); thus, the results that use better established validity scales such as NIM and Fp-r are more likely to be trusted at this point.

Our underreporting results contradict Edens et al.'s (2001) and Book et al.'s (2006) findings that those who successfully faked good were significantly higher on psychopathic traits than were those who were detected. The results of the current investigation also contradict MacNeil and Holden's (2006) findings that individuals who successfully faked good were higher on Machiavellian egocentricity and blame externalization, and lower on stress immunity, than individuals who were detected. It is possible that these results contradict those from the current investigation due to the use of measures without well-established utility in detecting response bias (e.g., the HPSI used in both Book et al., 2006, and MacNeil and Holden, 2006). Holden and Evoy (2005) reported that the HPSI validity scale correlated strongly $(-.59$ to -.88$)$ with the Social Desirability scale of the Personality Research Form (PRF; Jackson, 1984), which more closely resembles the L-r scale than the K-r scale. Thus, these two different methods of assessing feigning good could account for the differences in findings between MacNeil and Holden (2006) and the current study. In addition, MacNeil and Holden (2006) classified individuals as "successful" or "not successful" fakers based on cutoff scores. It is possible that this method resulted in misclassification of individuals. In addition, MacNeil and Holden (2006) conducted $t$ tests to determine significant differences in mean psychopathy scores between faking and honest groups. While they did find some significant results (e.g., for Machiavellian egocentricity, blame externalization, and stress immunity), the effect sizes were generally small to moderate (e.g., $d \mathrm{~s}=.40$ to .60 ) and not consistent across any one domain of the psychopathic personality (i.e., in the current study, each of these PPI scales loaded on three separate domains). Another possible reason for the contradictory results is the use of different assessments of psychopathy. It is possible that our threefactor model captures a more comprehensive conceptualization of psychopathy compared with the measures used in these other studies, especially with regard to the mean, cold characteristics of psychopathy (i.e., the PPI does not fully capture meanness; see Patrick et al., 2009).

One possible explanation for the current findings for K-r could be that "mean" or coldhearted psychopaths might have more difficulty feigning psychological adjustment than do individuals low on such psychopathic traits. Perhaps the emotional detachment and poor perspective-taking ability that individuals high on this psychopathy factor exhibit make it difficult for them to take the perspective of what emotional adjustment look like in others. Certainly, considerable research has determined a neurobiologically mediated empathy deficiency in individuals with psychopathy (e.g., Blair, 2007). Thus, when attempting to appear more psychologically adjusted than they really are, they overcompensate in their presentations 
and therefore score higher on K-r while doing so. Further research is needed to elaborate on these hypotheses.

As discussed earlier, psychopathy was not associated with any better or worse ability to avoid detection by the L-r scale, which assesses unlikely virtues; that is, common and obvious personal flaws that most individuals would be willing to endorse. These are potentially easier to feign successfully, given the fact that this is a less sophisticated and more superficial method of feigning. Indeed, Baer and Miller (2002) demonstrated in a meta-analysis on the MMPI-2 validity scales that when individuals are coached on the validity scales, $\mathrm{L}$ is associated with a much smaller effect size in differentiating underreporting from honest participants relative to $\mathrm{K}$. Thus, individuals who score high on the meanness domain of psychopathy are more likely to avoid detection by a scale that focuses on uncommon virtuous than psychological adjustment.

Overall, when integrating the results of the present investigation with the previous literature, the preponderance of well-designed studies tend to show that individuals high on psychopathic traits are no better able to avoid detection on validity scales than individuals low on these traits in terms of overreporting. In terms of underreporting, the combined evidence suggests that individuals high on psychopathic traits are no better able than individuals low in such traits to avoid detection on validity scales when attempting to make themselves appear socially desirable. However, specific features of psychopathy may affect an individual's ability to successfully feign psychological adjustment without being detected, such that some features (e.g., meanness) decrease this ability, while others (e.g., stress immunity) may increase it.

The current findings have implications for forensic psychological evaluations. In general, individuals high on psychopathic traits are not better able to present themselves in an overly positive or negative light than those low on these traits, which is an encouraging finding. When individuals do try to present themselves in an inaccurate light, the MMPI-2-RF validity scales evidenced utility in distinguishing between those feigning and those who responded honestly. Because individuals in forensic evaluations often have an incentive to respond in an overly positive or negative manner (e.g., Rogers \& Cruise, 2000), it is important that response bias be assessed in forensic evaluations to determine whether or not an individual is trying to provide an inaccurate picture of him- or herself. Given the information that individuals high in psychopathic traits may be more likely to malinger, it is especially important that these individuals be assessed for response bias.

Although we made significant efforts to address some of the methodological issues found in previous studies, the current investigation is nonetheless also associated with some limitations. In regard to the underreporting analyses, we were not able to replicate the analyses in a known-groups sample due to the fact that Study 2 utilized a sample of convenience. With respect to the overreporting analyses, the sample in Study 2 was small and may not have been sufficiently powerful to detect a statistically significant moderation effect. However, the effect size, which is what we used to determine a moderation effect (i.e., $\Delta R^{2} \geq .02$ ), is not dependent on sample size. Furthermore, the results were entirely consistent with Study 1 and the extant literature. One other possible limitation is that using different methods of assessment (e.g., PCL-R vs. PPI, SIRS vs. simulation instructions) makes it difficult to directly compare results from these two studies. However, these differences in assessment could also be considered a strength, given replication across settings and assessment modalities as well as the consistency of the findings.

Despite these limitations, the current investigation does have significant strengths. Use of two methodologies (analogue simulation and known-groups) allows for both internal control and generalizability to forensic clinical populations. The use of multiple measures of psychopathy (both several self-report inventories and the PCL-R) allowed us to examine some of the various conceptualizations of psychopathy that have been proposed to date, without relying on only one particular viewpoint. We also used measures with well-established utility in detecting over- and underreporting (e.g., the MMPI-2-RF).

Future research in this area should investigate underreporting in additional samples, such as forensic samples in which individuals might have significant motivation to present themselves in an overly positive light (e.g., individuals undergoing preemployment or custody evaluations). Focus on the "meanness" domain of psychopathy in such studies might, if replicated, provide further insight as to why they are less able than individuals high on other psychopathic traits and "normal" individuals to feign psychological adjustment. Because those high on meanness presented themselves differently than those high on boldness or disinhibition, it is possible that there may be other differential manifestations between the groups, such as degree or type of antisocial behaviors. Although psychopathy in general did not appear to be associated with moderating effects on the ability to avoid detection on validity scales, it is possible that other variables may have such effects. An individual's level of psychological knowledge and training does not appear to aid in avoiding detection when feigning (e.g., Marion et al., 2011). However, other forms of knowledge (e.g., verbal and quantitative abilities) may increase an individual's ability to avoid detection on validity scales. There is also the possibility that an interaction could be present between psychopathy and another variable, such that individuals high on psychopathy and high on intelligence would be better able than individuals low on both of these constructs to avoid detection on validity scales when feigning.

\section{References}

Baer, R. A., \& Miller, J. (2002). Underreporting of psychopathology on the MMPI-2: A meta-analytic review. Psychological Assessment, 14, $16-$ 26. doi:10.1037/1040-3590.14.1.16

Bagby, R. M., Marshall, M. B., Bury, A. S., Bacchiochi, J. R., \& Miller, L. S. (2006). Assessing underreporting and overreporting response styles on the MMPI-2. In J. N. Butcher (Ed.), MMPI-2: A practitioner's guide (pp. 39-69). Washington, DC: American Psychological Association.

Benning, S. D., Patrick, C. J., Hicks, B. M., Blonigen, D. M., \& Krueger, R. F. (2003). Factor structure of the Psychopathic Personality Inventory: Validity and implications for clinical assessment. Psychological Assessment, 15, 340-350. doi:10.1037/1040-3590.15.3.340

Ben-Porath, Y. S., \& Tellegen, A. (2008). Minnesota Multiphasic Personality Inventory-2 Restructured Form: Manual for administration, scoring, and interpretation. Minneapolis, MN: University of Minnesota Press.

Blair, R. J. R. (2007). Empathic dysfunction in psychopathic individuals. In T. F. D. Farrow \& P. W. R. Woodruff (Eds.), Empathy in mental illness (p. 3-16). New York: Cambridge University Press.

Book, A. S., Holden, R. R., Starzyk, K. B., Wasylkiw, L., \& Edwards, M. J. (2006). Psychopathic traits and experimentally induced deception in self-report assessment. Personality and Individual Differences, 41, 601608. doi:10.1016/j.paid.2006.02.011

Brinkley, C. A., Diamond, P. M., Magaletta, P. R., \& Heigel, C. P. (2008). 
Cross-validation of Levenson's Psychopathy Scale in a sample of federal female inmates. Assessment, 15, 464-482.

Brinkley, C. A., Schmitt, W. A., Smith, S. S., \& Newman, J. P. (2001). Construct validation of a self-report psychopathy scale: Does Levenson's self-report psychopathy scale measure the same constructs as Hare's psychopathy checklist-revised? Personality and Individual Differences, 31, 1021-1038. doi:10.1177/1073191108319043

Butcher, J. N., Graham, J. R., Ben-Porath, Y. S., Tellegen, A., Dahlstrom, W. G., \& Kaemmer, B. (2001). Minnesota Multiphasic Personality Inventory-2: Manual for Administration and Scoring (2nd ed.). Minneapolis, MN: University of Minnesota Press.

Cohen, J. (1988). Statistical power analysis for the behavioral sciences (2nd ed.). Hillsdale, NJ: Erlbaum.

Drislane, L. E. (2011, May). The triarchic model of psychopathy: An international perspective. In L. E. Drislane (Chair), The triarchic model of psychopathy: An international perspective. Symposium conducted at the meeting of the Society for the Scientific Study of Psychopathy, Montreal, Canada.

Edens, J. F. (2006). Unresolved controversies concerning psychopathy: Implications for clinical and forensic decision making. Professional Psychology: Research and Practice, 37, 59-65. doi:10.1037/07357028.37.1.59

Edens, J. F., Buffington, J. K., Tomicic, T. L., \& Riley, B. D. (2001). Effects of positive impression management on the psychopathic personality inventory. Law and Human Behavior, 25, 235-256. doi:10.1023/ A: 1010793810896

Edens, J. F., Poythress, N. G., \& Watkins-Clay, M. M. (2007). Detection of malingering in psychiatric unit and general population prison inmates: A comparison of the PAI, SIMS, \& SIRS. Journal of Personality Assessment, 88, 33-42. doi:10.1207/s15327752jpa8801_05

Ekman, P. (1985). Telling lies. New York, NY: Norton.

Gervais, R. O., Ben-Porath, Y. S., Wygant, D. B., \& Sellbom, M. (2010). Incremental validity of the MMPI-2-RF over-reporting scales and RBS in assessing the veracity of memory complaints. Archives of Clinical Neuropsychology, 25, 49-55. doi:10.1093/arclin/acq018

Hare, R. D. (1991). The Hare Psychopathy Checklist-Revised. Toronto, ON: Multi-Health Systems.

Hare, R. D. (1993). Without conscience: The disturbing world of the psychopaths among us. New York, NY: Simon \& Schuster.

Hare, R. D. (1996). Psychopathy: A clinical construct whose time has come. Criminal Justice and Behavior, 23, 25-54. doi:10.1177/ 0093854896023001004

Hare, R. D. (2003). Hare Psychopathy Checklist-revised manual (2nd ed.). Toronto, ON; Multi-Health Systems.

Hathaway, S. R., \& McKinley, J. C. (1940). A multiphasic personality schedule (Minnesota): I. Construction of the schedule. Journal of Psychology, 10, 249-254.

Hawes, S. W., \& Boccaccini, M. T. (2009). Detection of over-reporting of psychopathology on the Personality Assessment Inventory: A metaanalytic review. Psychological Assessment, 21, 112-124. doi:10.1037/ a0015036

Holden, R. R. (1996). Holden Psychological Screening Inventory manual. North Tonawanda, NY: Multi-Health Systems.

Holden, R. R., \& Evoy, R. A. (2005). Personality inventory faking: A four-dimensional simulation of dissimulation. Personality and Individual Differences, 39, 1307-1318.

Horn, J. L. (1965). A rationale and a test for the number of factors in factor analysis. Psychometrika, 30, 179-185.

Iverson, G. L., Franzen, M. D., \& Hammond, J. A. (1995). Examination of inmates' ability to malinger on the MMPI-2. Psychological Assessment, 7, 118-121. doi:10.1037/1040-3590.7.1.118

Jackson, D. N. (1984). Personality Research Form manual (3rd ed.). Port Huron, MI: Sigma Assessment Systems.

Kaiser, H. F. (1960). The application of electronic computers to factor analysis. Educational and Psychological Measurement, 20, 141-151. doi:10.1177/001316446002000116

Kucharski, L. T., Duncan, S., Egan, S. S., \& Falkenbach, D. M. (2006). Psychopathy and malingering of psychiatric disorder in criminal defendants. Behavioral Sciences \& the Law, 24, 633-644. doi:10.1002/ bsl.661

Leistico, A. R., Salekin, R. T., DeCoster, J., \& Rogers, R. (2008). A large-scale meta-analysis relating the Hare measures of psychopathy to antisocial conduct. Law and Human Behavior, 32, 28-45. doi:10.1007/ s10979-007-9096-6

Levenson, M. R., Kiehl, K. A., \& Fitzpatrick, C. M. (1995). Assessing psychopathic attributes in a noninstitutionalized population. Journal of Personality and Social Psychology, 68, 151-158. doi:10.1037/00223514.68.1.151

Lilienfeld, S. O., \& Andrews, B. P. (1996). Development and preliminary validation of a self-report measure of psychopathic personality traits in noncriminal populations. Journal of Personality Assessment, 66, 488 524. doi:10.1207/s15327752jpa6603_3

Lilienfeld, S. O., \& Fowler, K. A. (2006). The self-report assessment of psychopathy: Promises, problems, and solutions. In C. Patrick (Ed.), Handbook of Psychopathy (pp. 107-132). New York, NY: Guilford Press.

Lilienfeld, S. O., \& Hess, T. H. (2001). Psychopathic personality traits and somatization: Sex differences and the mediating role of negative emotionality. Journal of Psychopathology and Behavioral Assessment, 23, 11-24. doi:10.1023/A:1011035306061

Lilienfeld, S. O., \& Widows, M. R. (2005). Psychopathic Personality Inventory - revised manual. Lutz, FL: Psychological Assessment Resources.

Lynam, D. R., Whiteside, S., \& Jones, S. (1999). Self-reported psychopathy: A validation study. Journal of Personality Assessment, 73, 110132. doi:10.1207/S15327752JPA730108

MacNeil, B. M., \& Holden, R. R. (2006). Psychopathy and the detection of faking on self-report inventories of personality. Personality and Individual Differences, 41, 641-651. doi:10.1016/j.paid.2006.03.004

Marion, B. E., Sellbom, M., \& Bagby, R. M. (2011). The detection of feigned psychiatric disorders using the MMPI-2-RF over-reporting validity scales: An analog investigation. Psychological Injury and Law, 4, 1-12. doi:10.1007/s12207-011-9097-0

Millon, T. (1987). Manual for the MCMI-II (2nd ed.). Minneapolis, MN: National Computer Systems.

Millon, T. (1997). Manual for the MCMI-III (2nd ed.). Minneapolis, MN: National Computer Systems.

Morey, L. C. (1991). Personality Assessment Inventory: Professional manual. Tampa, FL: Psychological Assessment Resources.

Morey, L. C. (1996). An interpretive guide to the Personality Assessment Inventory (PAI). Tampa, FL: Psychological Assessment Resources.

Morey, L. C. (2007). Personality Assessment Inventory (PAI) professional manual (2nd ed.). Odessa, FL: Psychological Assessment Resources.

Mullins-Nelson, J. L., Salekin, R. T., \& Leistico, A. R. (2006). Psychopathy, empathy, and perspective -taking ability in a community sample: Implications for the successful psychopathy concept. International Journal of Forensic Mental Health, 5, 133-149.

Patrick, C. J. (2010). Triarchic psychopathy measure (TriPM). PhenX Toolkit Online Assessment Catalog (https://www.phenxtoolkit.org/ index.php?pageLink $=$ browse. protocoldetails $\& i d=121601$ ).

Patrick, C. J. (2010, March). Operationalizing the triarchic model of psychopathy: Brief scales for assessment of Boldness, Meanness, and Disinhibition. Symposium conducted at the 2010 American PsychologyLaw Society Conference. Vancouver, British Columbia, Canada.

Patrick, C. J., Fowles, D. C., \& Krueger, R. F. (2009). Triarchic conceptualization of psychopathy: Developmental origins of disinhibition, boldness, and meanness. Development and Psychopathology, 21, 913938. doi:10.1017/S0954579409000492 
Paulhus, D. L. (1998). The Balanced Inventory of Desirable Responding. Toronto, ON: Multi-Health Systems.

Poythress, N. G., Edens, J. F., \& Watkins, M. M. (2001). The relationship between psychopathic personality features and malingering symptoms of major mental illness. Law and Human Behavior, 25, 567-582. doi: 10.1023/A:1012702223004

Rogers, R. (2008). An introduction to response styles. In R. Rogers (Ed.), Clinical assessment of malingering and deception (2nd ed., pp. 3-13). New York, NY: Guilford Press.

Rogers, R., Bagby, R. M., \& Dickens, S. E. (1992). Structured Interview of Reported Symptoms. Tampa, FL: Psychological Assessment Resources.

Rogers, R., \& Cruise, K. R. (2000). Malingering and deception among psychopaths. In C. B. Gacano (Ed.), The clinical and forensic assessment of psychopathy: A practitioner's guide (pp. 269-284). Mahwah, NJ: Erlbaum.

Rogers, R., Sewell, K. W., Morey, L. C., \& Ustad, K. (1996). Detection of feigned mental disorders on the Personality Assessment Inventory: A discriminant analysis. Journal of Personality Assessment, 67, 629-640. doi:10.1207/s15327752jpa6703_15

Sellbom, M. (2011). Elaborating on the construct validity of the Levenson Self-Report Psychopathy Scale in incarcerated and non-incarcerated samples. Law and Human Behavior, 35, 440-451. doi:10.1007/s10979101-9249-x

Sellbom, M., \& Bagby, R. M. (2008a). Response styles on multiscale inventories. In R. Rogers (Ed.), Clinical assessment of malingering and deception (2nd ed., pp. 182-206). New York, NY: Guilford Press.

Sellbom, M., \& Bagby, R. M. (2008b). Validity of the MMPI-2-RF (Restructured Form) L-r and $\mathrm{K}-\mathrm{r}$ scales in detecting underreporting in clinical and nonclinical samples. Psychological Assessment, 20, 370376. doi:10.1037/a0012952

Sellbom, M., \& Bagby, R. M. (2010). Detection of overreported psychopathology with the MMPI-2-RF form validity scales. Psychological Assessment, 22, 757-767. doi:10.1037/a0020825

Sellbom, M., \& Phillips, T. R. (in press). An Examination of the Triarchic Conceptualization of Psychopathy in Incarcerated and Non-Incarcerated Samples. Journal of Abnormal Psychology.
Sellbom, M., Toomey, J. A., Wygant, D. B., Kucharski, L. T., \& Duncan, S. (2010). Utility of the MMPI-2-RF (Restructured Form) Validity Scales in detecting malingering in a criminal forensic setting: A knowngroups design. Psychological Assessment, 22, 22-31. doi:10.1037/ a0018222

Toomey, J. A., Kucharski, L. T., \& Duncan, S. (2009). The utility of the MMPI-2 Malingering Discriminant Function Index in the detection of malingering: A study of criminal defendants. Assessment, 16, 115-121. doi: $10.1177 / 1073191108319713$

Vaughn, M. G., Newhill, C. E., DeLisi, M., Beaver, K. M., \& Howard, M. O. (2008). An investigation of psychopathic features among delinquent girls: Violence, theft, and drug abuse. Youth Violence and Juvenile Justice, 6, 240-255. doi:10.1177/1541204007312298

Vitacco, M. J., Rogers, R., Gabel, J., \& Munizza, J. (2007). An evaluation of malingering screens with competency to stand trial patients: A known-groups comparison. Law and Human Behavior, 31, 249-260. doi:10.1007/s10979-006-9062-8

Walters, G. D. (2003). Predicting criminal justice outcomes with the Psychopathy Checklist and Lifestyle Criminality Screening Form: A meta-analytic comparison. Behavioral Sciences and the Law, 21, 89102. doi:10.1002/bsl.519

Wygant, D. B., Ben-Porath, Y. S., Arbisi, P. A., Berry, D. T. R., Freeman, D. B., \& Heilbronner, R. L. (2009). Examination of the MMPI-2 Restructured Form (MMPI-2-RF) validity scales in civil forensic settings: Findings from simulation and known group samples. Archives of Clinical Neuropsychology, 24, 671-680. doi:10.1093/arclin/acp073

Wygant, D. B., Sellbom, M., Gervais, R. O., Ben-Porath, Y. S., Stafford, K. P., Freeman, D. B., \& Heilbronner, R. L. (2010). Further validation of the MMPI-2 and MMPI-2-RF Response Bias scale: Findings from disability and criminal forensic settings. Psychological Assessment, 22, 745-756. doi:10.1037/a0020042

Received December 14, 2011

Revision received June 6, 2012 Accepted June 12, 2012 